\title{
Internal curing of high performance concrete using cenospheres
}

Department of Civil, Construction and Environmental Engineering, The University of Alabama,

Tuscaloosa, AL 35487, United States

\section{ABSTRACT}

6 This study explores a novel internal curing agent, perforated cenospheres. Cenospheres are

7 hollow fly ash particles produced from coal burning power plants. The shell of the cenospheres is

8 inherently porous that is sealed by a thin layer of glass-crystalline film. By removing this film

9 through chemical etching, the pores on the shell can be exposed, perforating the cenospheres and

10 providing paths for water propagating into the internal volume of cenospheres. The perforated

11 cenosphere were found to have water absorption as high as $180 \mathrm{wt} . \%$. The loaded water can be

12 readily released from the cenospheres under high relative humidity $(95 \%)$. When incorporating

13 saturated cenospheres into cement mortar for internal curing, the autogenous shrinkage of the

14 mortar was almost eliminated. The internal curing also improved the compressive strength of the

15 cement mortar. All these results suggest that perforated cenospheres can be used as an efficient

16 internal curing agent for HPC.

18 Keywords: Internal curing, High performance concrete, Cenospheres, Autogenous shrinkage,

19 Early-age cracking

${ }^{*}$ Corresponding author. Tel.: +1-305-3486786; fax: +1-205-348-0783.

E-mail address: jwang@eng.ua.edu 


\section{Introduction}

22 Autogenous shrinkage is an important phenomenon in early age concrete, in which water can

23 be rapidly drawn into the hydration process and the demand for more water creates very fine

24 capillaries. The surface tension within the capillaries causes autogenous shrinkage which can

25 lead to premature cracks, making the concrete more vulnerable to the ingress of potentially

26 aggressive species and thus severely reducing the durability of concrete. Early age cracking due

27 to autogenous shrinkage is especially serious for high-performance concrete (HPC) because of its

28 low water to cement ratio [1]. These cracking problems cannot be mitigated through

29 conventional full water curing due to HPC's compact structure and very low permeability. To

30 combat this problem, internal curing method has been developed in which water-filled internal

31 curing agents are added to concrete mixture. These internal curing agents are used as water

32 reservoirs which can gradually release its water during the hydration process. The released water

33 can maintain a high relative humidity inside the concrete pores to prevent self-desiccation in

34 concrete [1]. As a result, autogenous shrinkage of concrete can be reduced or eliminated, which

35 will ultimately minimize cracking and significantly promote the durability of structural concrete

$36[2,3]$. More complete cement hydration is also achieved by internal curing due to extra curing

37 water provided by the internal curing agent, creating a denser cement paste, reducing

38 permeability $[1,4,5]$. As a result, the service life of concrete structures can be significantly

39 increased and the life-cycle cost can be significantly reduced [6].

40 The key element in internal curing technique is to choosing a proper internal curing agent to

41 load and release water in concrete as needed. An ideal internal curing agent should release most

42 of its absorbed water uniformly at high relative humidity within an appropriate time [1] in order

43 to optimize internal curing of concrete [7]. The most often used internal curing agents are pre- 
44 wetted high porosity lightweight aggregates (LWAs) and super absorbent polymers (SAPs) [1].

45 LWAs include lightweight coarse aggregates (LWCAs) with a particle size greater than $6.35 \mathrm{~mm}$ 46 and lightweight fine aggregates (LWFAs) with a particle size smaller than $6.35 \mathrm{~mm}$. Pre-wetted

47 LWFAs are more suitable than LWCAs because of two reasons [8]: 1) LWFAs can produce

48 better distribution of moisture; and 2) LWCAs don't have the approximate gradation of the

49 natural aggregate being replaced. SAPs can expand to absorb thousands of times their dry

50 weight in water without dissolving, although commercially available SAPs generally exhibit

51 absorbency below $20 \mathrm{~g} / \mathrm{g}$. When used in cement to entrain water, the high $\mathrm{pH}$ environment of the

52 concrete mixture can substantially reduce the absorption extent of SAPs compared to pure water.

53 Nevertheless, the SAPs can absorb much more water to be used in internal curing than LWAs.

54 Although great success has been achieved by these two internal curing agents, they can be

55 further improved to minimize the adverse effect on the mechanical properties $[9,10]$ induced by

56 the internal curing agents. This is because in nature the internal curing agent is much weaker

57 than normal aggregates. To this end, the amount of necessary internal curing agent should be

58 minimized [7]. By using the concept of protected paste volume, Bentz and Snyder [11] found

59 that cement paste should lie within a sufficiently small distance from the internal curing water

60 reservoir so that the internal water could penetrate. Within this distance, the cement paste is

61 protected by the internal curing water from self-desiccation. Clearly, smaller spacing between

62 internal curing agent particles is more desirable because more cement paste can be protected by

63 the internal curing water. To achieve this, the internal curing agent particle size should be as

64 small as possible [7]. Some experimental studies [12] did show that smaller internal curing agent

65 particles perform better than the larger ones. Zhutovsky et al. [13] also found that reduction of

66 the internal curing particle size down to 4-2 $\mathrm{mm}$ can improve the curing efficiency. However, 
67 further reduction of the internal curing agent particles led to reduction of internal curing

68 efficiency, instead of increase. Zhutovsky et al. [7] found that this apparent discrepancy was

69 caused by two competing mechanisms taking place upon reduction of the particle size of the

70 internal curing agent: i) small spacing factor can increase the internal curing efficiency; while ii)

71 small particles have smaller pores which tend to hold water more tightly, making them

72 unavailable for internal curing. When the particle size is sufficiently small, the second

73 mechanism overrides the first mechanism, leading to reduction in internal curing efficiency.

74 Therefore, to obtain optimal internal curing result, only reducing the spacing between particles is

75 not sufficient. The structure of the internal curing agent particles must be optimized too. To

76 make water more available to internal curing, the size of the pore in the internal curing agent

77 particles should be as large as possible. Theoretically, the largest size for a pore should be the

78 size of the particle itself. However, the currently used internal curing agents, neither LWAs nor

79 SAPs can have such a pore structure.

80 In this study, a novel internal curing agent with such an optimal pore structure, perforated

81 cenospheres is proposed for internal curing of HPC. Cenospheres are hollow fly ash particles

82 generated in coal burning power plants, which have sizes ranging from a few to hundreds of

83 micrometers (Fig. 1(a)). Cenospheres are much smaller than LWAs, thus they can provide better

84 distribution of curing water. Since they have only one large pore, which is very close to their

85 own size, as shown in Fig. 1(b), water can be loaded into and released from them easily.

86 Moreover, cenosphere particles have an aluminosilicate shell with high stiffness and strength and

87 a thickness of just a few micrometers. The potential of using cenospheres to deliver water was

88 noticed by Jensen and Lura [14] 10 years ago. They stated that "If water-filled, the capsule wall

89 (of cenosphere) could have beneficial pozzolanic properties whereas the water might serve as 
90 internal curing water." However, they have never been implemented because the shell of

91 cenospheres is covered by a glass-crystalline nanosize film (Fig. 1(a)). Without removing this

92 thin film, the inner volume of the cenosphere is inaccessible to water, as shown in Fig. 1(a).

93 Jensen and Lura [14] also pointed out that "no method to induce the water into the particles or to

94 ensure its proper release when needed seems to be available."

95 In this work, this barrier has been removed through removing the thin film by a simple

96 chemical etching process. Water can then be easily induced into or released out of cenospheres

97 through the holes perforating the shell of the cenospheres. It is found from this research that

98 perforated cenospheres have a water absorption as high as $180 \mathrm{wt} . \%$, and the loaded water can be

99 readily released from cenospheres under high relative humidity of $95 \%$. When mixing the

100 saturated cenospheres into mortars, the autogenous shrinkage can be eliminated without

101 compromising the compressive strength. These findings suggest that the perforated cenospheres

102 have a great potential to be used as an efficient internal curing agent for HPC.

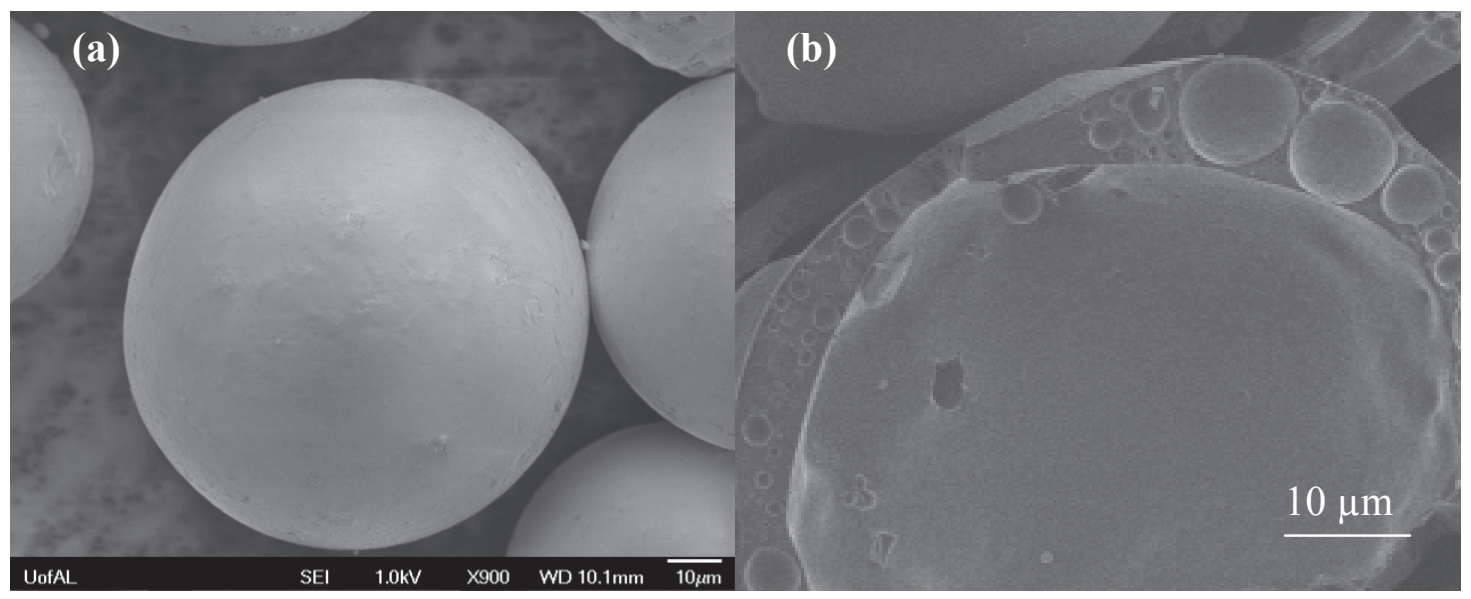

104 Fig. 1. Microstructure of cenospheres under SEM observation: (a) a cenosphere with impermeable shell; (b) porous shell of the cenosphere. 


\section{Materials and Methods}

109 2.1. Materials

110 In current study, reagent grade ammonium fluoride $\left(\mathrm{NH}_{4} \mathrm{~F}\right)$ and hydrochloric acid $(\mathrm{HCl})$ were

111 used. Calcium gluconate gel was always present during handling of hydrofluoric based acid

112 solution (1.0 $\left.\mathrm{M} \mathrm{NH}_{4} \mathrm{~F}-1.2 \mathrm{M} \mathrm{HCl}-\mathrm{H}_{2} \mathrm{O}\right)$.

113 Cenospheres used have sizes between 10 and $200 \mu \mathrm{m}$. Table 1 shows the chemical

114 composition of cenospheres, gained by X-ray fluorescence (XRF) analysis. The composition of

115 Type I Portland cement used for casting mortar is also listed in Table 1. It has to be pointed out

116 that XRF technique can provide excellent quantification for many elements in the periodic table

117 except those with low atomic weights, e.g., oxygen. In an effort to compensate for the matrix

118 effects of the compounds routinely compromising the solids, the XRF software offers the option

119 to represent the elemental concentrations as oxides. For cement-based materials, comparing and

120 contrasting 'oxide equivalent' within a sample can provide a more helpful and representative

121 metric relative to a comparison of elemental concentrations [19,20,27]. Thus in this paper, the

122 XRF data is reported as oxide compositions.

\section{2.2. Production of perforated cenospheres with acid etching}

124 Cenosphere particle has an aluminosilicate shell with a thickness in a few micrometers (Fig.

125 1(a)). The shell has a porous structure formed by gas inclusion and is covered by a glass-

126 crystalline nanosize film, which is shown in Fig. 1(b). To make the internal volume of

127 cenospheres accessible for water, the film should be removed. This can be done by etching the

128 cenospheres with acids [15]. Approximately $12 \mathrm{~g}$ of cenospheres were soaked into $250 \mathrm{~mL}$ of 1.0

$129 \mathrm{M} \mathrm{NH}_{4} \mathrm{~F}-1.2 \mathrm{M} \mathrm{HCl}-\mathrm{H}_{2} \mathrm{O}$ solution for 2 hours with occasional stir. By the end of this treatment,

130 more than $95 \%$ of cenosphere sank to the bottom of container, which were floating on the 
131 surface of acid solution at the beginning. The settlement of cenospheres indicates the completion

132 of perforation. After etching, the perforated cenospheres were vacuum filtered and rinsed with

$1331500 \mathrm{~mL}$ of water, followed by being dried in an oven at $110^{\circ} \mathrm{C}$.

134 The morphology and microstructure of as-received (Fig. 1) and the produced perforated

135 cenospheres were investigated using a JOEL $7000 \mathrm{FE}$ scanning electron microscope (SEM). The

136 microscope was operated at low accelerating voltage $(1 \sim 3 \mathrm{kV})$ and $10 \mathrm{~mm}$ working distance with

137 a spot size of medium 8. Before being put into SEM chamber, cenospheres were coated with a

138 layer of gold, in order to mitigate the charging effect.

Table 1. Chemical composition of cenospheres and Type I Portland cement

\begin{tabular}{ccc}
\hline Compound & $\begin{array}{c}\text { As-received } \\
\text { Cenospheres, } \%\end{array}$ & $\begin{array}{c}\text { Type I Portland } \\
\text { Cement, \% }\end{array}$ \\
\hline $\mathrm{SiO}_{2}$ & 57.35 & 22.93 \\
$\mathrm{Al}_{2} \mathrm{O}_{3}$ & 31.93 & 4.68 \\
$\mathrm{CaO}$ & 0.44 & 64.04 \\
$\mathrm{Fe}_{2} \mathrm{O}_{3}$ & 2.27 & 2.41 \\
$\mathrm{TiO}_{2}$ & 1.17 & 0.20 \\
$\mathrm{MgO}$ & 0.54 & 3.38 \\
$\mathrm{Na} 2$ & 0.54 & 0.23 \\
$\mathrm{~K}_{2} \mathrm{O}$ & 1.40 & 0.76 \\
$\mathrm{P}_{2} \mathrm{O}_{5}$ & 0.06 & 0.08 \\
$\mathrm{MnO}$ & N/A & 0.07 \\
\hline
\end{tabular}

141 2.3. Absorption and desorption behaviors of perforated cenospheres

142 Determination of the water absorption was obtained by measuring the weight difference

143 between the oven dry and saturated surface dry (SSD) cenospheres. The procedures of obtaining

144 SSD cenospheres were based on the ASTM C128 [16]. Water can be loaded into perforated

145 cenospheres simply by mixing them together. When cenospheres all sank down to the bottom of

146 the water container, the loading of cenospheres with water was completed. The saturated

147 cenospheres were then filtered and placed in a cone slightly tamped for 25 times, and the cone 
148 was removed. The cone tests rely on the principle of surface tension for determining when the

149 surface moisture disappears. When the moisture is still on the surface of the cenosphere, surface

150 tension of the water will hold the particles in the form of the cone after the cone is removed.

151 When no moisture is present on the surface, slight slumping of the cenosphere cone will occur,

152 which means the cenospheres achieve the SSD condition. Then the SSD cenospheres were

153 collected and weighted. Thereafter, they were dried in an oven at $110{ }^{\circ} \mathrm{C}$ for 48 hours to calculate

154 the absorbed water percentage, which was found to be around $180 \%$ by weight of the oven dry

155 cenospheres.

156 When used for internally curing the concrete, water loaded in cenospheres has to be readily

157 released to the surrounding cementitious matrix under high relative humidity. Thus, a study was

158 conducted to evaluate the water release behavior of the cenospheres under two different relative

159 humidity (RH) levels: $95 \%$ and $50 \%$. The $\mathrm{RH}$ of $95 \%$ and $50 \%$ simulate the moisture condition

160 in the cement paste at the very early and late ages, respectively. In addition, these two humidity

161 levels could also represent the moist environment under the moist and air curing, as specified in

162 ASTM C511 [17]. The oven-dry, perforated cenospheres were placed in water first. When the

163 cenospheres sank at the bottom of the container, they were removed from water by vacuum

164 filtering. At this point, the saturated cenospheres were obtained. Thereafter, SSD cenospheres are

165 obtained by the applying the cone test as described above. Then a $5.0 \pm 0.0001 \mathrm{~g}$ of SSD

166 cenospheres were placed in a tarred quartz pan with a diameter of $\sim 15 \mathrm{~cm}$. The pan containing

167 the sample was then suspended from the balance $( \pm 0.0001 \mathrm{~g}$ accuracy) and placed in a relative

168 humidity chamber to equilibrate at $23 \pm 1{ }^{\circ} \mathrm{C}$ and $50 \%$ or $95 \%$ relative humidity until the sample

169 had achieved a stable mass (mass change is less than $0.0001 \mathrm{~g} / 15 \mathrm{~min}$ ). The weight of the sample 
170 was recorded at an interval of 15 minutes. After equilibrating, the samples were dried at $110^{\circ} \mathrm{C}$

171 for 48 hours to calculate the dry weight of the perforated cenospheres used.

172 2.4. Vicat needle measurement

173 Saturated cenospheres were integrated into cement paste to evaluate the effect of internal

174 curing on the setting time of cement paste. The pastes had a w/c ratio of 0.35 , which fell into the

175 range of w/c ratios for high performance concrete $(0.45 \sim 0.21)$ [18-20]. Addition of saturated

176 cenospheres was designed to provide $9 \%$ of internal curing water by weight of cement,

177 corresponding to $5 \%$ of oven-dry, perforated cenospheres that have a water absorption of 180

178 wt.\%. This amount of internal curing water was appropriate for compensating the moisture loss

179 caused by cement hydration [1,21]. For comparison purpose, setting time of control paste

180 samples was also studied, including those without any cenospheres and with $5 \%$ of

181 nonperforated cenospheres.

182 All the cement pastes were mixed according to the ASTM C305 [22]. For the cement paste

183 with internal curing, the weighted oven-dry, perforated cenospheres were saturated with the total

184 amount of mixing and internal curing water first. After all the perforated cenospheres has been

185 settled down to the bottom of water container, the mixture was then mixed with cement to

186 prepare the cement paste. The control samples were prepared by directly mixing the dry

187 materials and water together.

188 The initial and final setting time of cement paste were determined by the Vicat needle tests, 189 which were carried out according to ASTM C191 [23]. When the needle penetrated into the 190 cement paste for $25 \mathrm{~mm}$, initial set was achieved. Final setting was attained when there was no

191 mark of the specimen surface with a complete circular impression. The tests on the control and 192 internally cured samples were repeated 3 times to ensure the precision of the determination. 


\subsection{Effects of internal curing on heat evolution}

194 Isothermal conduction calorimetry was also implemented on the cement pastes with a w/c

195 ratio of 0.35 , based on ASTM C1702 [24]. For the internally cured pastes, dry perforated

196 cenospheres was added in the amount of $3.33 \%$ and $5 \%$ by weight of cement, providing $6 \%$ and

$1979 \%$ additional water for internal curing, respectively. As it is known that typically the internal

198 curing water does not exceed $6 \%$ by weight of cement used [20,21]. But it could also be

199 interesting to examine whether extra water provided by cenospheres beyond $6 \%$ can further

200 improve the internal curing efficiency or not. Thus in addition to the $6 \%$, the effect of providing

$2019 \%$ internal curing water was also studied. Control samples without any cenospheres or with 5\%

202 nonperforated cenospheres were also tested for their heat signatures.

203 An Isothermal calorimeter (I-Cal 2000 HPC Isothermal Calorimeter) was employed to

204 monitor the heat evolution in all the cement pastes. Before testing, the calorimeter was regulated

205 at constant temperature of $22 \pm 1{ }^{\circ} \mathrm{C}$ and then equilibrated for 24 hours. All the cement pastes

206 were mixed by pan mixer and cast into a plastic cup that is specially crafted to fit the calorimeter

207 channels. Each sample contained $50.0 \mathrm{~g}$ of Portland cement. The freshly mixed cement pastes

208 were promptly placed into the channels of the calorimeter. The heat evolution within 7 days after

209 mixing was recorded continuously. It should be mentioned that external stirring of cement paste

210 will lead to non-meaningful heat of hydration during the very initial period. Therefore,

211 integration of the accumulative heat was started from 20 minutes so that the error in the initial

212 period could be minimized.

\section{2.6. Internal curing efficiency of perforated cenospheres}

214 Saturated cenospheres were integrated into cement mortar to evaluate its internal curing

215 efficiency in terms of mortar's autogenous shrinkage and compressive strength. The mix 
216 proportions are listed in Table 2. There were four mix proportions used, the control mortar

217 without cenospheres (Control_0\%) or with 5\% nonperforated cenospheres (as-received

218 cenospheres) (Control_9\%), the mortar with 6\% internal curing water by weight of cement

219 (IC_6\%), and the mortar with 9\% internal curing water (IC_9\%). The amount of superplasticizer

220 was adjusted for obtaining the similar workability for the four mixes. It can be seen from the

221 table that cenospheres are not included as cementitious material in the mixes. Instead, they

222 replace some volume originally occupied by sand in the control sample without cenospheres. The

223 inclusion of cenospheres slightly reduces the water to binder (w/b) ratio of the mortar if the

224 cenospheres are treated as binder. Nevertheless, this will not interfere with the analysis of the

225 effect of internal curing on the mortar properties because internal curing water participates in

226 cement hydration at early age when pozzolanic reaction of cenospheres is minimal.

Table 2. Mix proportion of mortar $\left(\mathrm{kg} / \mathrm{m}^{3}\right)$

\begin{tabular}{l|cccc}
\hline Constituent & Control_0\% & Control_9\% & IC_6\% & IC_9\% \\
\hline Cement & 592.0 & 592.0 & 592.0 & 592.0 \\
Water & 207.2 & 207.2 & 207.2 & 207.2 \\
Sand & 1539.2 & 1432.6 & 1468.9 & 1432.6 \\
$\begin{array}{l}\text { Nonperforated } \\
\text { cenospheres }\end{array}$ & - & 29.6 & - & - \\
$\begin{array}{l}\text { Perforated } \\
\text { cenospheres }\end{array}$ & - & - & 19.5 & 29.6 \\
$\begin{array}{l}\text { Internal curing } \\
\text { water }\end{array}$ & - & - & 35.2 & 53.3 \\
Superplasticizer & 3.0 & 3.0 & 1.8 & 1.8 \\
\hline
\end{tabular}

230 (cement and/or unperforated cenospheres), water, and sand were mixed homogeneously

231 according to the ASTM C305 [22]. For the mortars with internal curing, the perforated

232 cenospheres were first mixed with calculated weight of water (both internal curing and mixing

233 water) to be saturated. Then the mixture was mixed with cement and sand together following the 
234 ASTM C305 [22]. After mixing, each mortar was cast into molds for the measurements of

235 autogenous shrinkage and compressive strength.

236 The autogenous shrinkage of the mortar was measured by an automated testing system

237 shown in Fig. 2, based on ASTM C1698 [25]. The mortar was cast into the molds consisting of

238 corrugated plastic tubes, having a length of $420 \pm 5 \mathrm{~mm}$ and an outer diameter of $29 \pm 0.5 \mathrm{~mm}$. The

239 small diameter of the molds limits the temperature differences that may arise during hydration of

240 the cementitious materials. As stated in the standard [25], the typical maximum temperature

241 increase in the center of test specimen, due to heat of hydration of mortar has been determined to

242 be $2{ }^{\circ} \mathrm{C}$. In addition, the mortars were stored under the controlled laboratory condition with

243 constant temperature of $23.0 \pm 1.0^{\circ} \mathrm{C}$ all the time. Based on all these, it can be assumed that the

244 deformation caused by thermal stress due to cement hydration is negligible, and it is validate to

245 take the measured length change as autogenous shrinkage. The automated testing system

246 measured the sample length continuously after final setting till 7 days with an interval of 10

247 minutes.

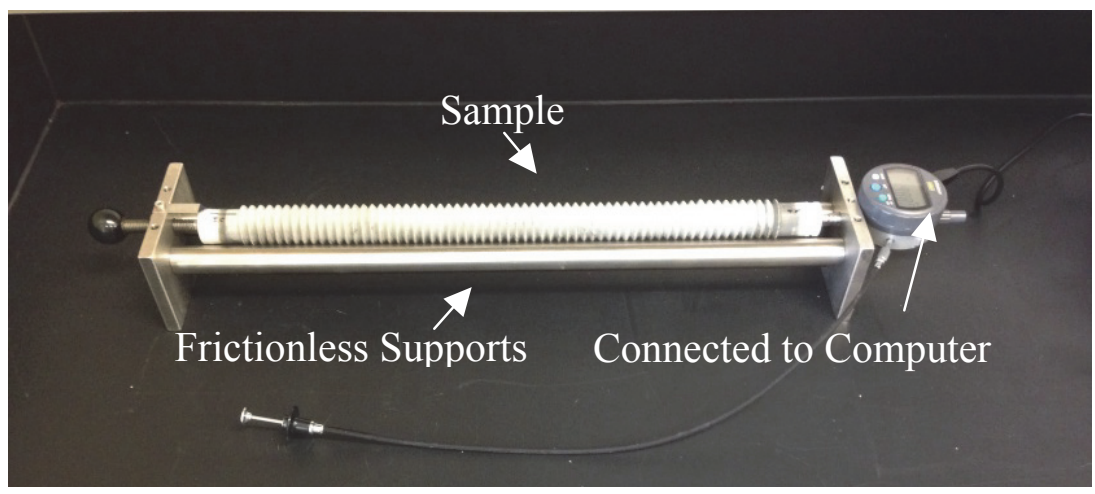

Fig. 2. Automated version of ASTM C1698 (2014) to measure the autogenous shrinkage of cement paste.

254 molds and compacted using a vibration table. After 24 hours, the samples were demolded and 
255 put into plastic bags for sealed curing at a controlled temperature of $23 \pm 1{ }^{\circ} \mathrm{C}$ till the designated

256 ages of 3,7 , and 28 days. At each age, compression test was carried out on three samples

257 according to the ASTM C109 [26]. The mortar samples were crushed into pieces with

258 appropriate size for SEM observation as well.

\section{3. Results and discussion}

\subsection{Microstructure of perforated cenospheres}

261 The original cenospheres represent a silicate-alumina-iron multiple component system with

262 the surface covered by glass-crystalline nanosize film (Fig. 1(a)). After acid etching with $1.0 \mathrm{M}$

$263 \mathrm{NH}_{4} \mathrm{~F}-1.2 \mathrm{M} \mathrm{HCl}-\mathrm{H}_{2} \mathrm{O}$ for 2 hours, this film was removed as shown in Fig. 3. Small holes with

264 size smaller than $2 \mu \mathrm{m}$ penetrating through the shell were introduced on the surface of the

265 cenosphere shell by the acid etching, through which water can be easily loaded into the hollow

266 particles. The porous structure of the shell of the cenosphere shown in Fig. 1(b) makes the

267 chemical etching extremely efficient since only the film covering the pores on the shell needs to 268 be removed.

269 Table 3 lists the chemical composition of cenospheres after acid treatment. Comparing with 270 the original composition (Table 1), the content of alumina was increased from 31.93 to $35.00 \%$

271 in the perforated cenospheres. This is because alumina was not subjected to the etching action

272 [15], while the silica and iron deposits on cenospheres were dissolved by the hydrofluoric based 273 acid system. The dissolution resulted in about $8.77 \%$ weight loss of the cenospheres shell. 


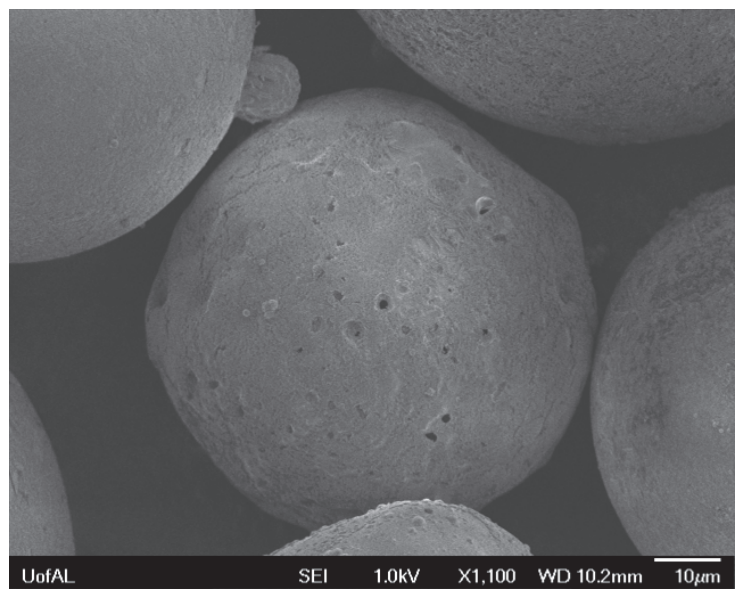

Fig. 3. SEM microphotograph of the perforated cenospheres after being etched with $1.0 \mathrm{M}$

$\mathrm{NH}_{4} \mathrm{~F}-1.2 \mathrm{M} \mathrm{HCl}-\mathrm{H}_{2} \mathrm{O}$ solution for 2 hours.

Table 3. Chemical composition of perforated cenospheres produced by acid etching

\begin{tabular}{cc}
\hline Compound & Perforated cenospheres, \% \\
\hline $\mathrm{SiO}_{2}$ & 57.81 \\
$\mathrm{Al}_{2} \mathrm{O}_{3}$ & 35.00 \\
$\mathrm{CaO}$ & 0.33 \\
$\mathrm{Fe}_{2} \mathrm{O}_{3}$ & 2.13 \\
$\mathrm{TiO}_{2}$ & 1.15 \\
$\mathrm{MgO}$ & 0.51 \\
$\mathrm{Na}_{2} \mathrm{O}$ & 0.52 \\
$\mathrm{~K}_{2} \mathrm{O}$ & 1.32 \\
$\mathrm{P}_{2} \mathrm{O}_{5}$ & 0.05 \\
\hline
\end{tabular}

281 3.2. Desorption behavior of perforated cenospheres

282 The perforated cenospheres were mixed with water. After all of them had settled at the

283 bottom of the water container, cenospheres were filtered and SSD cenospheres were obtained

284 through the method described in Section 2.3. These cenospheres were studied for their water

285 desorption behavior under the two different RH levels. The results are shown in Fig.4. In the

286 environmental chamber with $\mathrm{RH}$ of $50 \%$, the SSD cenospheres achieved equilibrium in 10 hours,

287 which took around 24 hours under RH of $95 \%$. And at equilibrium, about $99.7 \%$ and $90.6 \%$ of 
288 loaded water was released from cenospheres under the RH of $50 \%$ and $95 \%$, respectively. This

289 could serve as a good foundation for taking cenospheres as internal curing agent, since most of

290 the autogenous shrinkage in Portland cement paste was found to occur from the moment of final

291 setting to $2 \sim 4$ days after mixing $[1,20,27]$. From the rate point of view, the water release from

292 cenospheres could promptly compensate for the self-desiccation which causes autogenous

293 shrinkage at the very early age.

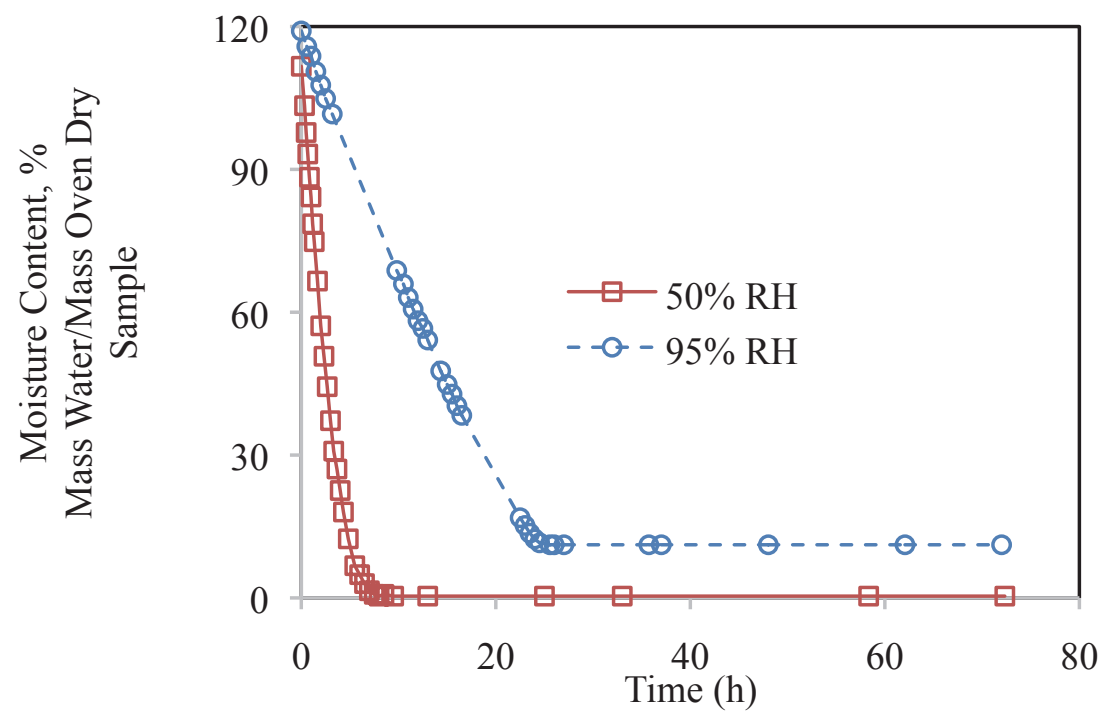

295 Fig.4. Water release behavior of the perforated cenospheres at RH levels of 50\% and 95\%.

296 3.3. Setting time and heat evolution

297 The saturated cenospheres were incorporated into cement paste to evaluate the effect of

298 internal curing on the hydration process as reflected by setting time and heat evolution. Fig.5

299 shows the penetration curves for both control and internally cured pastes. Based on these curves,

300 the initial and final setting time are found to be $2.2 \mathrm{~h}$ and $5.9 \mathrm{~h}$ for sample without cenospheres

301 (Control_0\%), $3.3 \mathrm{~h}$ and $7.1 \mathrm{~h}$ for sample with 5\% nonperforated cenospheres (Control_9\%), and

$3023.8 \mathrm{~h}$ and $8.0 \mathrm{~h}$ for internally cured sample (IC_9\%). These indicate that setting of paste is

303 slightly extended by the inclusion of nonperforated cenospheres, which is further retarded in the

304 internally cured sample. With the inclusion of 5\% nonperforated cenospheres, both the initial and 
305 final setting of the paste are retarded by about 1 hour, compared with the control sample without 306 cenospheres. This can be attributed to the dilution effect with the inclusion of cenospheres.

307 Testing of setting time is carried out on cement paste. While keeping the same $\mathrm{w} / \mathrm{c}$ ratio, the

308 inclusion of $5 \mathrm{wt} . \%$ of dry cenospheres occupies a portion of volume that belongs to cement and

309 water, comparing to the control sample without cenospheres. This dilutes the concentration of

310 cement and water proportionally in the tested volume of paste. As it is known that cenospheres

311 are actually hollow fly ash particles that are not reactive at early age. Thus the dilution of cement

312 and water by cenospheres resulted in the slower setting of cement paste. From Fig. 5, further

313 retardation in internally cured pastes is also found and it could be caused by the release of

314 additional water from cenospheres. The similar phenomena were also observed by other

315 researchers $[28,29]$.

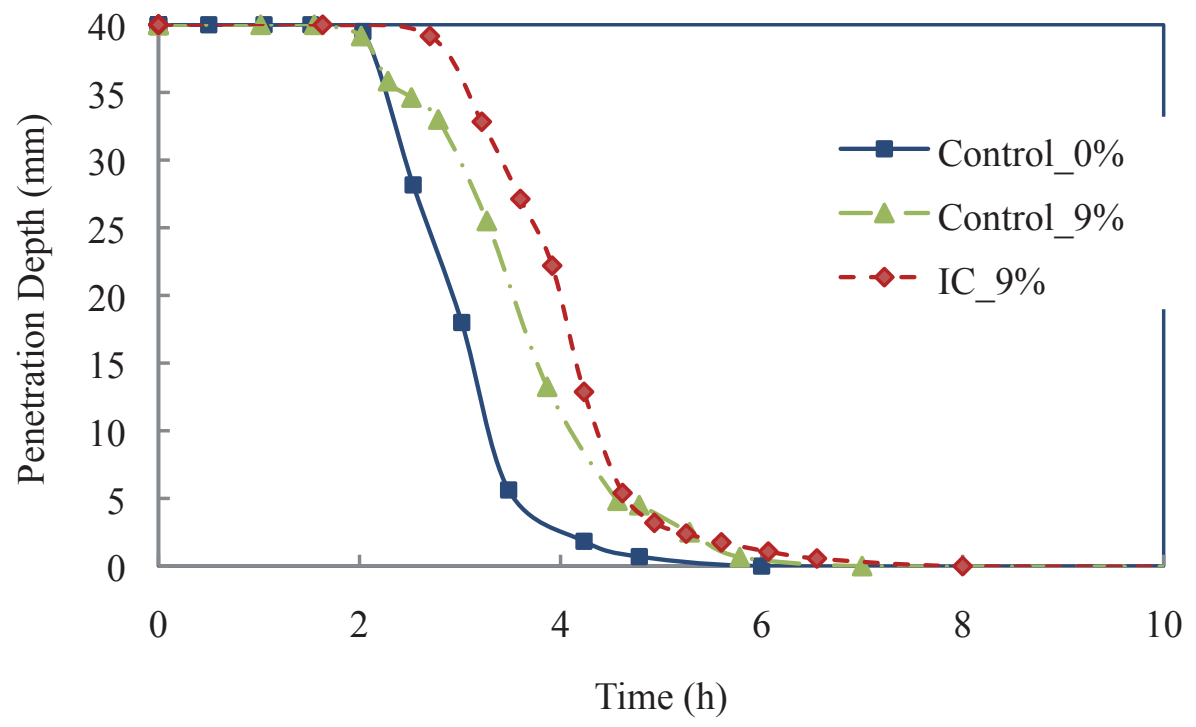

$317 \quad$ Fig.5. Vicat needle penetration curves for the control and internally cured cement pastes.

318 Fig. 6 plots the measured heat evolution curves for the pastes studied. From Fig. 6(a), two

319 peaks are observed at the time between 7 and 11 hours. The first peak is caused by the reaction

320 of $\mathrm{C}_{3} \mathrm{~S}$, while the second peak should be attributed to the reaction between gypsum and more 
321 available aluminate that is from the continuous cement dissolution [30]. It is also found from Fig.

322 6(a) that the integration of either nonperforated or perforated cenospheres slightly reduce the

323 height of main peaks and shift the peaks to the right, in comparison with the peaks in

324 Control_0\%. Peak reduction indicates that maximum heat release rate from cement hydration is

325 lower, while the right shift of the peak means that it takes longer for cement paste to achieve the

326 highest hydration rate. Both of these reveal the slower hydration in the pastes with cenospheres.

327 This corresponds well to the longer setting time in these samples, as seen in Fig. 5. Slower the

328 hydration, longer the initial and final setting will take. The lower peak for the sample of

329 Control_9\% could be caused by the fact that some of the mixing water is being used for wetting

330 the surface of the dry nonperforated cenospheres. Less water available for cement to react slows

331 down the heat releasing rate from hydration. Slight reduction and right shift of the main peak for

332 the internally cured samples were also observed by other researchers either using LWAs or SAPs

333 for internal curing $[20,29,31]$.

334 Fig. 6(b) compares the total amount of heat released from mortar samples with/without

335 internal curing. According to the figure, the heat of hydration from all the mortars is close to

336 each other in the first few hours. Then the hydration proceeds much slower in the control sample

337 with nonperforated cenospheres (Control_9\%). As discussed above, this could be caused by the

338 less water available for cement hydration, since part of the mixing water is taken to wet the dry

339 surface of the nonperforated cenospheres, lowering the hydration rate of cement. It is also

340 remarkable that pastes with saturated cenospheres release much higher amount of hydration heat

341 than the control one with only nonperforated cenospheres, even slightly higher than the control

342 sample without any cenospheres. This indicates that the water in the perforated cenospheres is 
343 participating in the hydration reactions. It has also been observed in previous researches that

344 internally cured sample released higher amount of hydration heat than control samples $[29,31,32]$.

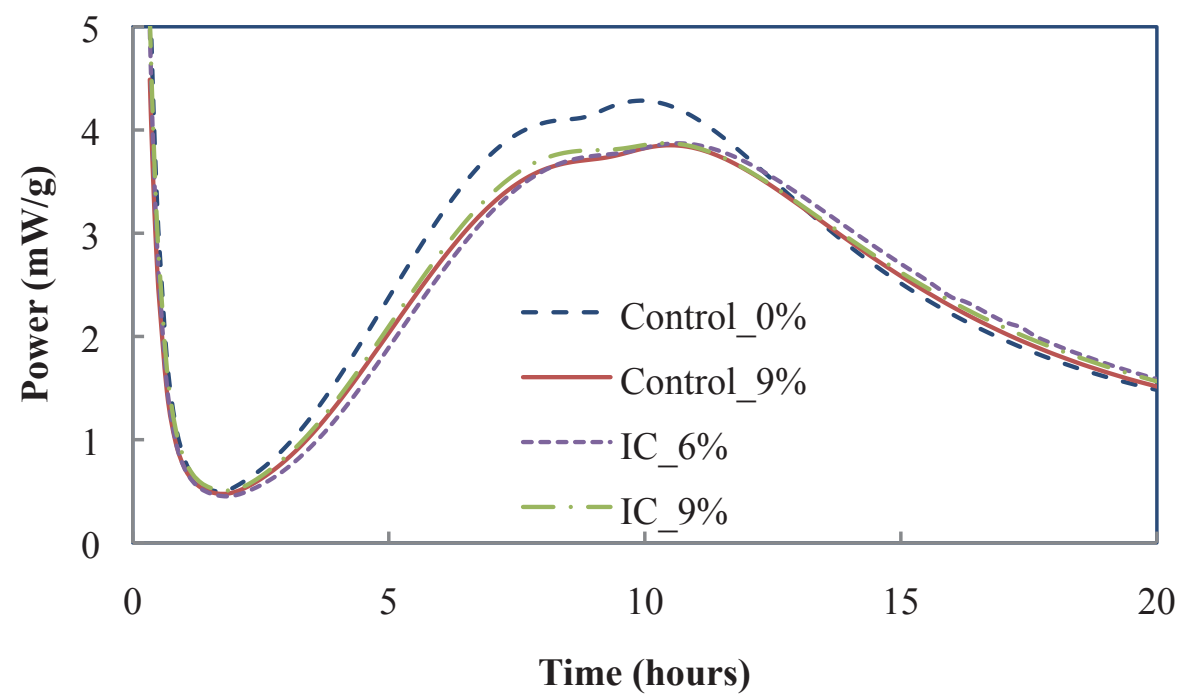

345

346

347

348

349 Fig. 6. Effect of internal curing on (a) the rate of heat evolution and (b) the total amount of heat

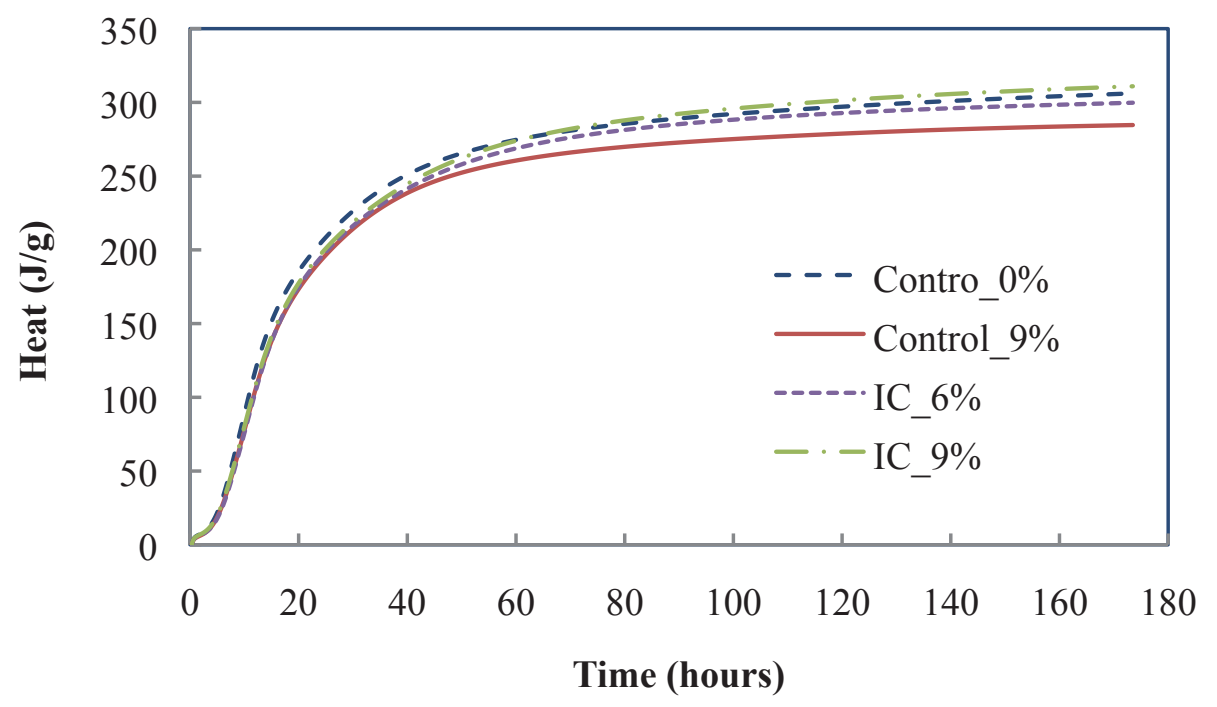

(b)

(a) released during hydration. 


\subsection{Autogenous shrinkage of mortars with or without internal curing}

354 The autogenous shrinkage of the control and internally cured mortars with w/c ratio of 0.35 is

355 shown in Fig. 7. Each sample was measured continuously from their respective final setting till 7

356 days. Before final setting, autogenous shrinkage will not occur since the mortar is still at the

357 plastic status. According to the shrinkage curves, it can be seen that the two control samples

358 shrink continuously within the measuring frame. The rapid shrinkage continued till 10 hours,

359 after which the samples shrink slowly and gradually. The ultimate shrinkage was around $120 \mu \varepsilon$

360 for the mortar without any cenospheres and $80 \mu \varepsilon$ for the one integrated with $5 \%$ nonperforated

361 cenospheres at 7 days. The smaller shrinkage induced by including nonperforated cenospheres

362 can be due to the less availability of water for cement hydration, since a portion of the water is

363 taken to wet the surface of dry nonperforated cenospheres during mixing, resulting in slower

364 hydration rate and smaller autogenous shrinkage.

365 From Fig. 7, a significant reduction of autogenous shrinkage is achieved in the internally

366 cured samples. The total shrinkage is less than $20 \mu \varepsilon$ for both samples with $6 \%$ and $9 \%$ internal

367 curing water at the age of 7 days. It is also noticeable from the figure that the internally cured

368 samples stop shrinking at about 24 hours, and then shrinkage keeps constant (IC_6\%) or the

369 mortar expands slightly (IC_9\%). Thus, it can be postulated that after 24 hours, the internal

370 curing provided by the saturated cenospheres can fully compensate for the self-desiccation

371 caused by cement hydration. If the amount of internal curing water is optimized, the elimination

372 of autogenous shrinkage can be expected. 


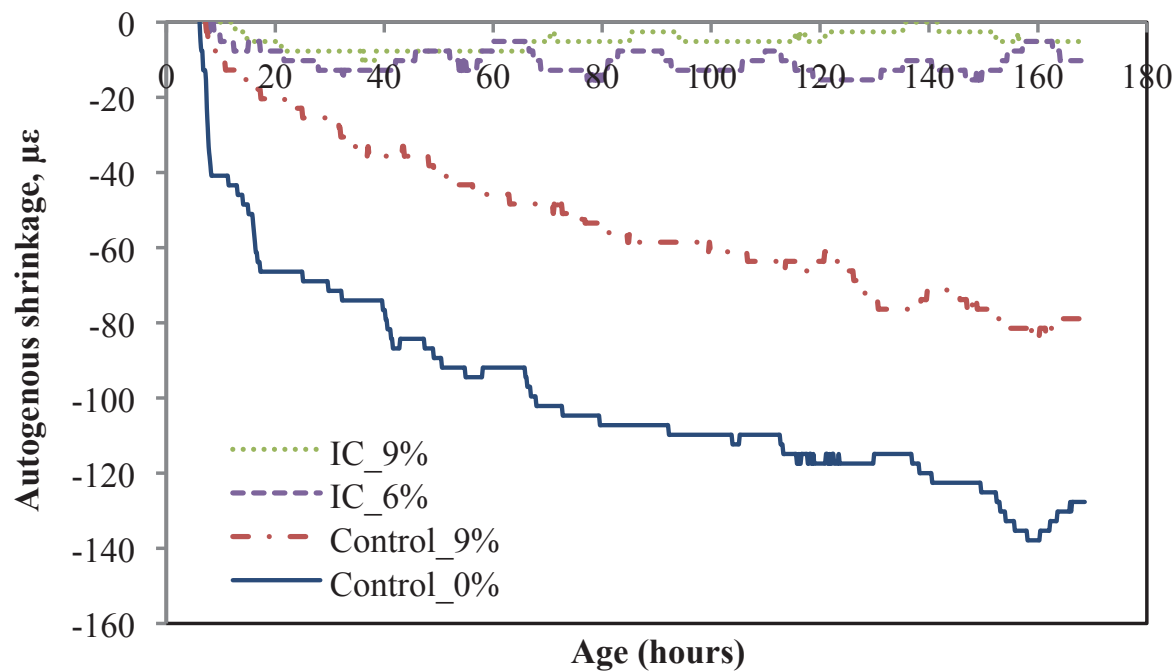

373

Fig. 7. Autogenous strain of control and internally cured cement mortars.

\subsection{Compressive strength}

Fig. 8 shows the compressive strength of mortars studied at the hydration age of 3,7 and 28 days. As mentioned in Section 2.6, the samples were cured under sealed condition, and the compression tests were carried out on three samples at each age for each mix. The average of the three was reported in the figure with error bars representing the standard deviation among them. From the chart, the compressive strength of the mortars increased when the hydration age was increased, regardless whether the mortars have been internally cured or not. With the integration of 5\% nonperforated cenospheres, the mortars have slightly lower compressive strength (3 5\%) than the control one without any cenospheres. This strength reduction can be attributed to the lower compressive strength of the hollow cenospheres in the mortar samples. According to the manufacturer, $90 \%$ of the cenospheres used in current work can resist compression up to 22.06 $\mathrm{MPa}$, which is lower than that of the mortar matrix. Hydraulic pressure method is used to measure the strength of cenospheres in which, cenospheres are loaded into a sealed container with water. Hydraulic pressure can then be applied to these cenospheres through a pump. The compressive strength of the cenospheres is determined based on the broken rates of cenospheres 
390 at specific hydraulic pressure. Previous work [33] using cenospheres as lightweight fillers also

391 shows that cenospheres can reduce the strength of concrete. With the comparison of the strength

392 data between Control_0\% and Control_9\%, the strength discrepancy between the two is not seen

393 to decrease as age increase. Thus it can be assumed that the pozzolanic reaction of cenospheres is

394 not active or does not contribute significantly to the strength. From the figure, the internal curing

395 effect can be found by comparing the strength between the control and internally cured mortars.

396 At the hydration age of 3 days, the compressive strength of the internally cured mortars was

397 lower than the control samples without any cenospheres. This could be caused by the lower

398 strength of cenospheres. When the mortars were cured for 7 and 28 days, the strength of the

399 internally cured samples caught up with the control ones, especially the one with $6 \%$ internal

400 curing water. At these ages, the mortar with $6 \%$ internal curing water had the highest

401 compressive strength. This can be caused by the promoted cement hydration with the extra water

402 released from the saturated cenospheres. Being cured under sealed condition, the mortar matrix

403 becomes short of moisture quickly with the fast cement hydration at early age, facilitating the

404 release of water from the saturated cenospheres. The released water can prolong the fast cement

405 hydration, leading to the faster strength development in the internally cured mortars. The

406 promoted hydration was able to compensate the strength loss caused by the lower strength of

407 cenospheres. The higher strength of internally cured sample was hardly achieved either by

408 LWAs or SAPs $[9,19,28]$. For example, inclusion of $0.3 \%$ by mass of cement providing $3 \sim 4 \%$

409 internal curing water led to approximately $10 \%$ reduction in the compressive strength of HPC at

41028 days [28]. Higher strength achieved by using cenospheres as internal curing agent can be

411 attributed to their perfect spherical shapes, which can minimize stress concentration in concrete 
412 induced by the voids of the internal curing agent. Thus the enhanced strength could be another

413 great advantage by using cenospheres for internal curing.

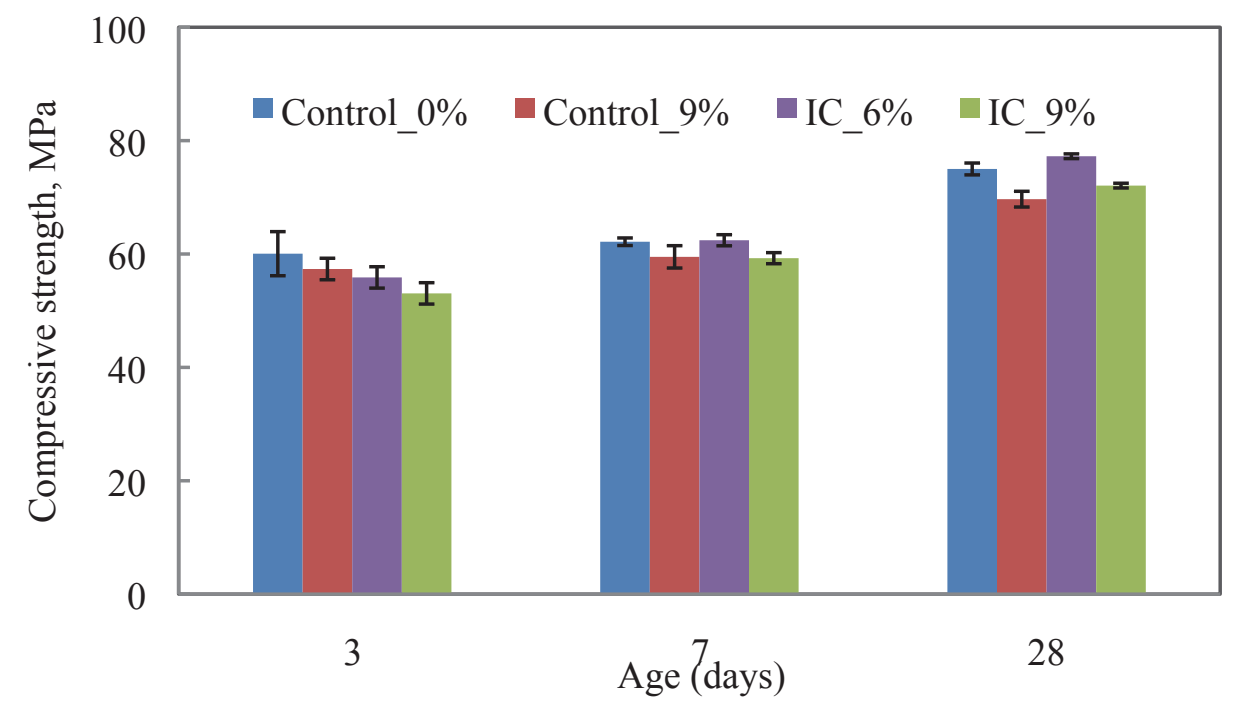

415 Fig.8. Measured compressive strength for mortars under sealed condition.

\section{3.6. Microstructure of cement mortar}

417 The microstructure of mortars at the age of 28 days was also investigated. The samples were

418 prepared as small fragment prized away from the failed cylindrical mortar specimens after

419 compression test. The fragments were mounted on Al stubs with carbon tape, vacuum dried for

42024 hours, Au sputter coated, and imaged in the high vacuum SEM mode. Evidence of cenosphere

421 particles was found to be well distributed throughout the hardened mortar microstructure, as

422 shown in Fig. 9. The dense microstructure of the mortar with w/c ratio of 0.35 can be clearly

423 seen. From the figure, a number of cenospheres are found, in the form of either intact spheres or

424 damaged particles. Fig. 10 shows the enlarged SEM images of intact cenosphere which were

425 present in Fig. 9. The presence of intact cenospheres indicates the superior mechanical strength

426 of cenospheres, which are able to withstand the shearing force from mechanical mixing. From

427 Fig. 10, the intact cenospheres are surrounded by various hydration products. These products 
428 could be precipitated from cement hydration and the possible reaction of cenospheres with

429 calcium hydroxide. In addition, one may notice a post-loading crack around the cenospheres and

430 the crack propagates into the adjacent microstructure. This indicates that compared to the

431 strength of mortar matrix, the bonding between the cenospheres and adjacent microstructure is

432 still lower. The bonding strength could be another factor that contributes to the lower strength of

433 mortar incorporating nonperforated cenospheres as shown in Fig.8.

Fig.9. Microstructure of mortar with $6 \%$ internal curing water at the hydration age of 28 days.

439 Fig. 10. Intact cenospheres in the cement mortar with $6 \%$ internal curing water with hydration
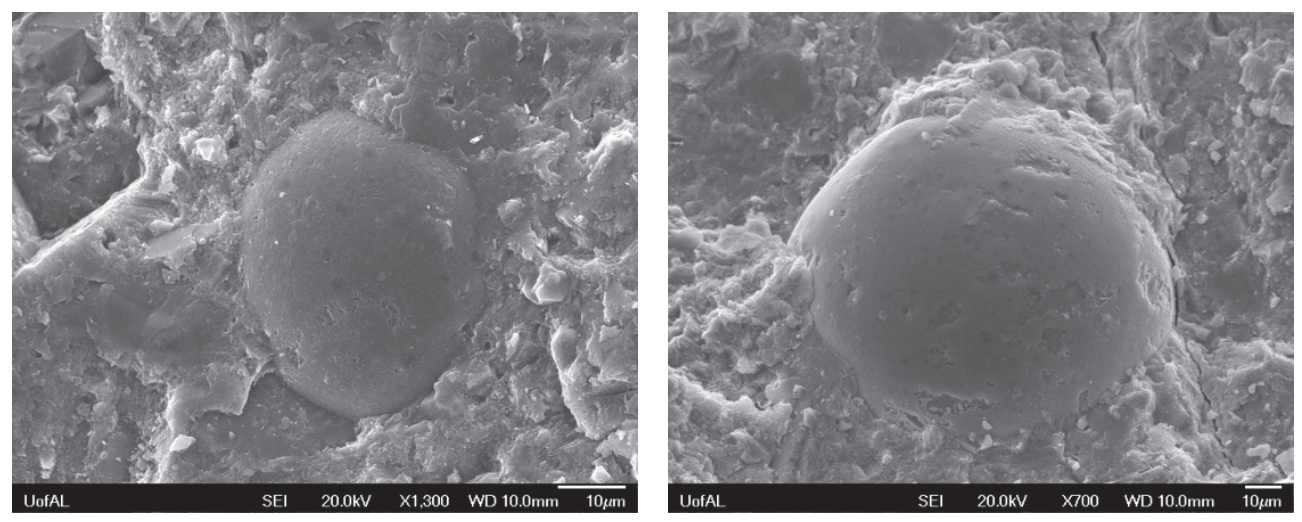


\section{Conclusions}

443 A chemical etching method is proposed in this study to produce perforated cenospheres so

444 that they can be used as internal curing agent for HPC. Based on the experimental results of this

445 work, the following conclusions can be drawn:

446 (a) Water can be induced into cenospheres through acid etching. The porous structure of the

447 cenosphere shell makes this etching process extremely efficient. The majority of pores

448 created on the shell are smaller than $500 \mathrm{~nm}$, with occasional pores in micron size $(<2 \mu \mathrm{m})$.

449 (b) The perforated cenospheres had water absorption as high as $180 \mathrm{wt} . \%$. The loaded water can

450 be readily released from the cenospheres in 24 hours under $\mathrm{RH}$ of $95 \%$.

451 (c) Internal curing provided by saturated cenospheres slightly retarded the setting of cement

452 paste.

453 (d) The internal curing was also found to lower the heat peak and shift the peak to the right. This

454 indicates the slower hydration rate, corresponding well to the slower setting in the internally

$455 \quad$ cured paste.

456 (e) With internal curing, autogenous shrinkage of mortar was reduced significantly. The mortar

457 stopped shrinking at around 24 hours, and it expanded slighted from 24 hours to 7 days. The

458 mortars without internal curing had much higher autogenous shrinkage, and it shrank

459 continuously with undergone hydration.

460 (f) Perforated cenospheres used as an internal curing agent in cement mortar mixture resulted in

461 slightly lower strength at early age, but with hydration progress, the compressive strength of

462 internally cured mortar was higher than the ones without internal curing at the ages of 7 and 28 days. 
In the future, internal curing by cenospheres will be optimized for HPC with various w/c

465 ratios between 0.45 and 0.21 , together with the incorporation of various supplementary

466 cementitious materials. In addition, some fundamental knowledge of this new technique will be

467 gained, including the role of fly ash particles in restrain the shrinkage of cement paste and the

468 possible improvement on pozzolanic reactivity of cenospheres by chemical treatment and their

469 effects on both the fresh and long-term durability of the cement-based materials.

\section{Acknowledgements}

471 The financial supports from the National Science Foundation (CMMI-1000580) and the

472 Research Stimulation Program at the University of Alabama are highly appreciated.

\section{References}

474 [1] D.P. Bentz, W.J. Weiss, Internal Curing : A 2010 State-of-the- Art Review, 2011. NISTIR 475 7765, U.S. Department of Commerce.

476 [2] R. Henkensiefken, T. Nantung, J. Wesis, Reducing Restrained Shrinkage Cracking in

477 Concrete: Examining the Behavior of Self-Curing Concrete Made using Different

478 Volumes of Saturated Lightweight Aggregate, in: Proc. Concr. Bridg. Conf., St Louis, 479 MO, 2008: pp. 1-14.

480 [3] P. Lura, J. Bisschop, On the origin of eigenstresses in lightweight aggregate concrete, 481 Cem. Concr. Compos. 26 (2004) 445-452.

482 [4] H. Al-Khaiat, M.N. Haque, Effect of initial curing on early strength and physical 483 properties of a lightweight concrete, Cem. Concr. Res. 28 (1998) 859-866.

484 [5] A. Radlinska, F. Rajabipour, B. Bucher, R. Henkensiefken, G. Sant, J. Weiss, Shrinkage 
Mitigation Strategies in Cementitious Systems: A Closer Look at Differences in Sealed and Unsealed Behavior, Transp. Res. Rec. J. Transp. Res. Board. 2070 (2008) 59-67.

487 [6] D. Cusson, Z. Lounis, L. Daigle, Benefits of internal curing on service life and life-cycle 488 cost of high-performance concrete bridge decks - A case study, Cem. Concr. Compos. 32 $489 \quad$ (2010) 339-350.

490 [7] S. Zhutovsky, K. Kovler, A. Bentur, Revisiting the protected paste volume concept for 491 internal curing of high-strength concretes, Cem. Concr. Res. 41 (2011) 981-986.

492 [8] J. Castro, L. Keiser, M. Golias, J. Weiss, Absorption and desorption properties of fine 493 lightweight aggregate for application to internally cured concrete mixtures, Cem. Concr. Compos. 33 (2011) 1001-1008.

495 [9] A. Bentur, S.I. Igarashi, K. Kovler, Prevention of autogenous shrinkage in high-strength 496 concrete by internal curing using wet lightweight aggregates, Cem. Concr. Res. 31 (2001) $497 \quad 1587-1591$.

498 [10] S. Zhutovsky, K. Kovler, a Bentur, Efficiency of lightweight aggregates for internal 499 curing of high strength concrete to eliminate autogenous shrinkage, Mater. Struct. 35 $500 \quad$ (2002) 97-101.

[11] D.P. Bentz, K.A. Snyder, Protected paste volume in concrete: Extension to internal curing 502 using saturated lightweight fine aggregate, Cem. Concr. Res. 29 (1999) 1863-1867. changes of lightweight aggregate concrete at early age, in: V. Baroghel-Bouny, P.-C. 
Aïtcin (Eds.), Int. RILEM Work. Shrinkage Concr., Paris, 2000: pp. 533-546.

506 [13] S. Zhutovsky, K. Kovler, A. Bentur, Assessment of Water Migration Distance in Internal 507 Curing of High-Strength Concrete, ACI SP-220. (2004) 181-197.

508 [14] O.M. Jensen, P. Lura, Techniques and materials for internal water curing of concrete, 509 Mater. Struct. 39 (2006) 817-825.

510 [15] Y. Xie, S.D. McAllister, D.B. Edwards, I.F. Cheng, Fabrication of porous hollow glass 511 microspheres, J. Power Sources. 196 (2011) 10727-10730.

512 [16] ASTM, C128-15 :Standard Test Method for Relative Density (Specific Gravity) and 513 Absorption of Fine Aggregate, West Conshohocken, PA, 2015.

514 [17] ASTM, C511-13 :Standard Specification for Mixing Rooms, Moist Cabinets, Moist 515

[19] X. Kong, Z. Zhang, Z. Lu, Effect of pre-soaked superabsorbent polymer on shrinkage of high-strength concrete, Mater. Struct. (2014) 2741-2758.

[20] S. Zhutovsky, K. Kovler, Hydration kinetics of high-performance cementitious systems under different curing conditions, Mater. Struct. 46 (2013) 1599-1611.

523 [21] S. Zhutovsky, K. Kovler, Chemical shrinkage of high strength/high-performance 524 cementitious materials, Int Rev Civ. Eng. 1 (2010) 110-118. 
525 [22] ASTM, C305-14: Standard Practice for Mechanical Mixing of Hydraulic Cement Pastes

526 and Mortars of Plastic Consistency, West Conshohocken, PA, 2014.

527 [23] ASTM, C191-13: Standard Test Methods for Time of Setting of Hydraulic Cement by

$528 \quad$ Vicat Needle, West Conshohocken, PA, 2013.

529 [24] ASTM, C1702-15b:Standard Test Method for Measurement of Heat of Hydration of $530 \quad$ Hydraulic Cementitious Materials Using Isothermal Conduction Calorimetry, West $531 \quad$ Conshohocken, PA, 2015.

532 [25] ASTM, C1698-09:Standard Test Method for Autogenous Strain of Cement Paste and 533 Mortar, West Conshohocken, PA, 2014.

534 [26] ASTM, C109/C109M-13: Standard Test Method for Compressive Strength of Hydraulic 535 536 Cement Mortars ( Using 2-in . or [ 50-mm ] Cube Specimens ), West Conshohocken, PA, 2010.

[27] Q.C. Nowasell, J.T. Kevern, Using drinking water treatment waste as low-cost internal curing agent for concrete, ACI Mater. J. 112 (2015) 69-77.

[28] V. Mechtcherine, M. Gorges, C. Schroefl, A. Assmann, W. Brameshuber, A.B. Ribeiro, et al., Effect of internal curing by using superabsorbent polymers (SAP) on autogenous shrinkage and other properties of a high-performance fine-grained concrete: results of a RILEM round-robin test, Mater. Struct. 47 (2013) 541-562.

D.P. Bentz, S.Z. Jones, M.A. Peltz, P.E. Stutzman, Influence of internal curing on properties and performance of cement-based repair materials, NISTIR 8076, U.S. 
546 [30] H.F.W. Taylor, Cement chemistry. 2nd, London, 1997: p. 188.

547 [31] J. Justs, M. Wyrzykowski, F. Winnefeld, D. Bajare, P. Lura, Influence of superabsorbent 548 polymers on hydration of cement pastes with low water-to-binder ratio: A calorimetry 549 study, J. Therm. Anal. Calorim. 115 (2014) 425-432.

550 [32] M. Wyrzykowski, S. Ghourchian, S. Sinthupinyo, N. Chitvoranund, T. Chintana, P. Lura, 551 Internal curing of high performance mortars with bottom ash, Cem. Concr. Compos. 71 $552 \quad$ (2016) 1-9.

553 [33] S.P. McBride, A. Shukla, A. Bose, Processing and characterization of a lightweight $554 \quad$ concrete using cenospheres. Journal of materials science. 37 (2002) 4217-4225. 